soluble in carbon tetrachloride, and $(c)$ a yellow pigment, possibly a derivative of the same metabolic pathway.

Department of Zoology,

A. E. NeEDHaM

University of Oxford.

Received January 17; revised February 5, 1968.

${ }^{1}$ Fox, H. M., and Vevers, G., The Nature of Animal Colours (Sidgwick and Jackson, London, 1960).

" Needham, A. E., and Brunet, P. C. J., Experientia, 13, 207 (1957).

s Needham, A. E., Comp. Biochem. Physiol., 1, 72 (1960).

Needham, A. E., Comp. Biochem. Physiol., 18, 427 (1966). semberg, R., and Legge, J. W., Haematin Compounds and Bile Pigments
(Interscience, New York, 1949).

"Kennedy, G. Y., and Dales, R. P., J. Mar. Biol. Assoc. UK, 37, 15 (1958).

${ }^{7}$ Mangum, C. P., and Dales, R. P., Comp. Biochem. Physiol., 15, 237 (1965).

- Charlot, G., and Bezier, D., Quantitative Inorganic Analysis (trans. by Murray, i. C.) (Methuen, London, 1957).

\section{Familial Behaviour of Tilapia (Pisces, Cichlidae) and its Implications}

Two types of familial organization are known in Tilapia and in cichlid fishes in general ${ }^{1}$. In the biparental type, which is considered to be the more primitive ${ }^{2,3}$, both partners participate in digging the nest and defending the territory. The eggs are deposited on the ground "substratum spawners") and both parents take care of them and of wrigglers and fingerlings for days or even weeks. Hundreds of young form a group which stays within the limits of the territory, and which is kept together by special movements of the parents. The bond between the parents is very strong 4,5 .

In most oral incubators, different males in a number of territories are successively visited by different females, whose eggs are thus fertilized in small batches ${ }^{8}$. As soon as a male has emitted his milt, the eggs are picked up in the female's mouth and she leaves the territory and retreats from the spawning ground to another area where she incubates the eggs orally. When they have absorbed their yolk sacs, the fingerlings can swim about freely, but they stay in a group near the female, following all her movements and retreating into her mouth when there is danger. By this time this familial group has generally reached shallow waters sheltered by plants.

Recent work ${ }^{7}$ has revealed something of the nature of the bond between the young and their parent(s). Batches of young fish, reared without parents, were exposed at different times to moving models. At about the age at which the rejection normally occurs the young of both $T$. mossambica Peters and T. macrochir Blgr., both of which are maternal brooders, immediately showed an orientation and following response when exposed to the moving model. This response was established at the time when the yolk sac was nearly reabsorbed (9-12 days after spawning) and was maintained until the time at which the young usually become independent of their mother (30 days arter spawning). If, however, the first exposure was made later (22-23 days after spawning), it was impossible to evoke a positive reaction; on the contrary, fear and escape behaviour occurred. This indicates that there is a precocious sensitive period for the establishment of the familial attachment which suggests that young are really imprinted in maternal-brooders.

In species of the biparental familial type (T. guineensis) territorial behaviour is shown until the young become independent; fingerlings do not show such an innate disposition to form a precocious attachment to the first moving object they meet. They can learn to follow a model, but only after several hours' exposure, so that it is impossible to determine the learning process responsible for the establishment of the attachment. Finally, in $T$. galilaea the young react towards the moving model in a manner similar to $T$. guineensis. From an ethological point of view, this species is intermediate between the two principal ethological groups: both parents incubate the eggs and the fry orally, but they aro territorial until the young become independent.

In substratum spawners, the young are born and develop at the place where their parents met, and they seem to be more linked to the territory and the substratum itself than to their parents. On the other hand, with females which incubate their young orally the young do not know the habitat where their parents met, for they are born away from the spawning ground. It is essential therefore for the young to be strongly linked to the incubating parent so that they can follow this parent when it moves.

We can assume that the acquisition of oral incubation and both peregrinating behaviour in the incubating parent and imprinting in the young represent a progressive step resulting in a greater independence of the fish from one type of habitat. This facilitates adaptive radiation, which in turn facilitates speciation. Most Tilapia species are known to be oral incubators, and only a few are sub. stratum spawners ${ }^{2,3}$.

In African waters where water level is periodically lowered, as in artificial lakes producing hydroelectric power, the substratum spawners are often obliged to leave their territory, whereupon the eggs and the fry are des. troyed and dried up. If they are free-swimming fingerlings, they stay within the limits of the territory and do not follow the retreating parents. On the other hand, there is no danger to the oral incubators, because the females leave the spawning grounds in search of deeper waters with their eggs and fry in their mouth and retreat with their fingerlings ${ }^{8}$. We know that the water levels of several African natural waters, such as Mweru Wantipa', are sometimes lowered; oral incubator species are better armed to face these fluctuations. With this in mind it has been suggested that ponds or artificial lakes which show fluctuations of water level should be charged with oral incubators only ${ }^{8}$.

Institut de Zoologie,

J. CL. Ruwet

Université de Liège,

Belgium.

Received July 31, 1967; revised January 22, 1968.

1 Baerends, G. P., and Baerends-Van Roon, J. M., Behaviour, Suppi. 1 (1950), 'Lowe, R. H., Proc. Zool. Soc., 132, 1 (1959).

${ }^{3}$ Thys, D. E. F., Bull. Séances ARSOM, 3, 570 (Brussels, 1963).

- Voss, J., and Ruwet, J. Cl., Ann. Soc. Roy. Zool. Belg., 96, 2, 145 (1960).

'Ruwet, J. Cl., and Voss, J., Bull. Scc. Roy. Sci. Liège, 35, 11, 778 (1966).

- Ruwet, J. Cl, Behaviour, 20, 3, 242 (1963).

7 Destexhe, F., and Ruwet, J. Cl., Ann. Soc. Roy. Zool. Belg., 97, 3, 161 (1967).

${ }^{8}$ Ruwet, J. Cl., Rev. Zool. Bot, Afric., 66, 3, 243 (1962).

${ }^{9}$ Brelsford. W. Y., The Northern Rhodesian Journal, 3 (Nov. 11. 1955).

\section{Mitotic Chromosomes of Glossina pallidipes Austen}

THE chromosomes of several species of tsetse-fly have been studied by Itard ${ }^{1}$. These include Glossina tachinoides Westwood and Glossina morsitans orientialis Vanderplank (Glossina morsitans morsitans Westwood in the terminology adopted by Itard). Glossina morsitans orientalis is one of the two main tsetse-flies which occur in Rhodesia, and so I thought it worthwhile for comparison to study the other, Glossina pallidipes Austen. The G. m. orientalis material used by Itard originated in Rhodesia.

Glossina pallidipes puparia were supplied by Dr R. J. Phelps and G. J. W. Dean of the Agricultural Research Council in Rhodesia. This material originated from collections of puparia from natural pupation sites near Kariba Township in the Zambezi Valley. The puparial contents were thus aged from $24 \mathrm{~h}$ (the time from the last collection to the arrival of the puparia at the laboratory) upwards, although the exact age of 